\title{
Digestibilidade in situ e cinética ruminal de bovinos de corte a pasto sob suplementação com proteinados ${ }^{1}$
}

\section{Luiz Orcírio Fialho de Oliveira² ${ }^{2}$ Eloísa de Oliveira Simões Saliba ${ }^{3}$, Lúcio Carlos Gonçalves ${ }^{3}$, Iran Borges ${ }^{3}$, Paula de Almeida Barbosa Miranda ${ }^{4}$, Maria Paula Ferreira Fialho ${ }^{4}$}

\footnotetext{
${ }^{1}$ Projeto financiado pelo CNPq.

2 Doutorando em Ciência Animal - UFMG.

${ }^{3}$ Departamento de Zootecnia da UFMG.

${ }^{4}$ Mestranda em Zootecnia - UFMG.
}

RESUMO - Foram estudados os efeitos da suplementação com proteinados sobre a degradabilidade da matéria seca (MS), proteína bruta (PB), fibra em detergente neutro e fibra em detergente ácido (FDN e FDA) em bovinos de corte em pastagem de Brachiaria brizantha cv. Marandu. Foram utilizados quatro bovinos Nelore com $395 \pm 9 \mathrm{~kg}$, fistulados no rúmen para avaliação da degradabilidade e da cinética da fase líquida e das partículas. Dois bovinos com fístulas esofagianas foram usados para a colheita de extrusas. Suplementos com 50, 40 e 30\% de proteína bruta (PB) foram fornecidos na proporção de $400 \mathrm{~g} / \mathrm{animal} / \mathrm{dia}$ em comparação à suplementação controle, com apenas sal mineral. A oferta de suplemento proteinado não influenciou a degradabilidade potencial da MS, PB e FDN, mas promoveu aumento de 36,85\% para 48,97\% na degradabilidade efetiva da MS e de 22,06\% para 30,05\% na degradabilidade da FDN. Os suplementos com 40 e 30\% de proteína bruta foram superiores ao controle, pois promoveram maior degradabilidade efetiva da PB e maiores taxas de saída das partículas. A taxa de passagem da fase líquida foi $11,4 \%$ maior nos animais que receberam os suplementos em relação aos do grupo controle. A degradabilidade efetiva da FDA não foi afetada pelo consumo dos suplementos e variou de 12,19\% (controle) a 16,75\% (suplemento com 30\% de $\mathrm{PB}$ ). Os resultados deste estudo mostram a importância da suplementação protéica para animais em pastagem de baixa qualidade e também do nível de $\mathrm{N}$ dos suplementos.

Palavras-chave: Brachiaria brizantha, degradabilidade, forragem tropical, suplemento proteico

\section{In situ digestibility and ruminal kinetics of steers receiving protein supplementation on pasture}

\begin{abstract}
The effects of protein supplementation on degradability of dry matter (DM), crude protein (CP) and neutral detergent fiber (NDF) and acid detergent fiber (ADF) were evaluated in beef cattle grazing Brachiaria brizantha cv Marandu. It was used four Nelore steers $(395 \pm 9 \mathrm{~kg})$ fitted with ruminal cannula to evaluate kinetics and degradability of the liquid phase and of the particles. Forage samples were collected in other two steers with esophageal cannula. Supplements with 50,40 , and $30 \%$ of crude protein (CP) were given at the proportion of $400 \mathrm{~g} / \mathrm{animal} / \mathrm{day}$ when compared to control suplementation with only salt and mineral. The offer of protein supplement did not change potential degradability of dry matter, crude protein and neutral detergent fiber but promoted an increase from $36.85 \%$ to $48.97 \%$ on effective degratability of dry matter and from $22.06 \%$ to $30.05 \%$ on neutral detergent fiber degradability. Supplements with 40 and $30 \%$ of crude protein were higher than the control because they promoted higher efffective degradability of crude protein and higher particle exit rates. The liquid passage rate was $11.4 \%$ higher for the animals which received supplementation when compared to the control. The effective degradability of ADF was not affect by consumption and it ranged from $12.19 \%$ (control) to $16.75 \%$ (supplement with $30 \%$ of crude protein). The results of this work show the importance of protein supplementation to animals on pasture of low quality and also the $\mathrm{N}$ level of the supplements.
\end{abstract}

Key Words: Brachiaria brizantha, degradability, protein supplement, tropical forage

\section{Introdução}

A produção de carne bovina depende da ingestão de nutrientes digestíveis e metabolizáveis (Weiss, 1994). Níveis de desempenho desejáveis na produção de bovinos de corte podem não ser atingidos quando a forragem apresenta baixos teores de proteína bruta (PB) e de digestibilidade, o que geralmente ocorre durante a estação seca na maior parte do Brasil tropical.

Suplementos proteinados têm sido intensamente utilizados neste período nos sistemas de produção a pasto (Thiago, 1998). Estudos sobre este processo de

Recebido em 1/10/2007 e aprovado em 25/5/2009.

Correspondências devem ser enviadas para: luizorcirio@hotmail.com 
suplementação têm comprovadomelhoria da digestibilidade e do consumo (Hess et al., 1994; Oliveira et al., 2004a, b). Os suplementos proteinados presentes no mercado brasileiro geralmente apresentam alta porcentagem de ureia ou amireia, que por sua elevada solubilidade, podem liberar quantidades excessivas de $\mathrm{N}-\mathrm{NH}_{3}$ (Cass et al., 1994), limitando a resposta microbiana e sua eficiência de síntese e degradação do alimento (Henessy \& Williamson, 1990; Song \& Kennely (1990); Hess etal., 1994; Arelovich etal., 2000).

Apesar de o $\mathrm{N}_{-} \mathrm{NH}_{3}$ ser a forma preferida de nitrogênio das bactérias que degradam fibras (Gorosito et al., 1985; Van Soest, 1994), ainda permanecem dúvidas sobre as concentrações ótimas deste no líquido ruminal. Satter \& Slyter (1974) indicaram concentrações de 2 a $5 \mathrm{mg} / \mathrm{dL}$ para otimizar o crescimento microbiano; Kang-Meznarich \& Broderick (1980), de 3,3 a 8,5 mg/dL para a fermentação e Mehrez et al. (1966), de 19 a 23 mg/dL para otimização da digestão da forragem.

A oferta sincronizada de nitrogênio e carboidratos melhora a eficiência de síntese microbiana, a ingestão de alimento e o consumo de energia (Oldham, 1984). Desta forma, a suplementação com proteinados pode melhorar o processo de fermentação ruminal (Hennessy et al., 1995), influenciando positivamente as taxas de passagem (Hess et al., 1994) e provocando um aumento no consumo de MS (Oliveira et al., 2004b). Não obstante, o aumento da taxa de passagem poderia reduzir a digestibilidade total (Ellis et al., 1994), o que não seria interessante para animais consumindo forragens de baixa digestibilidade. No entanto, a queda da digestibilidade pode ser compensada pelo aumento na absorção de nutrientes (Russell et al., 1992).

O objetivo neste estudo foi avaliar a cinética e a degradabilidade dos nutrientes no rúmen de bovinos em pastagem de baixo valor nutricional recebendo suplementos proteinados.

\section{Material e Métodos}

O experimento foi conduzido na Fazenda Rancho Alegre, localizada em Campo Grande (Mato Grosso do Sul) em uma área de 4 hectares formada por Brachiaria brizantha cv Marandu entre 17 de junho e 7 de outubro de 2002.

Foram preparados quatro animais da raça Nelore com peso vivo aproximado de $395 \pm 9 \mathrm{~kg}$, canulados no rúmen, e utilizados quatro períodos de 28 dias: 14 dias de adaptação e 14 dias de colheita (5 para a fase de digestibilidade, 5 para o estudo da cinética, e 4 dias de intervalo entre colheitas).

Os suplementos proteicos foram fornecidos na quantidade de $400 \mathrm{~g} / \mathrm{cabeça/dia,} \mathrm{nos} \mathrm{níveis} \mathrm{de} \mathrm{50,} 40$ e 30\% de proteína bruta $(\mathrm{PB})$ para comparação à suplementação controle, com apenas sal mineral (Tabela 1).

Os animais foram mantidos em pastagens de Brachiaria brizantha cv Marandu, distribuídos em quatro piquetes com área de 1,0 ha cada, com oferta diária do suplemento e retirada das sobras. Dois animais providos de fístula esofágica foram utilizados nas colheitas de extrusa, que foram realizadas segundo metodologia descrita por Euclides et al. (1992), com auxílio de sacolas de fundo telado para evitar acúmulo de saliva, e afiveladas por cintas ao pescoço e ao dorso dos animais.

As amostras mensais de extrusa foram conservadas em isopor com gelo e armazenadas em câmaras frias para análises químicas posteriores. Amostras compostas de extrusa coletadas no mês de junho foram usadas nos ensaios de digestibilidade nas análises químicas.

Nos ensaios de digestibilidade in situ, foram utilizados sacos de náilon com porosidade de $50 \mu \mathrm{m}$ e 20 $\mathrm{cm}$ de altura por $10 \mathrm{~cm}$ de largura (Forage Bags-Tectrigo ${ }^{\circledR}$ ). Uma argola de metal com aproximadamente $2 \mathrm{~cm}$ de diâmetro e foi colocada na extremidade aberta de cada saco, que foi fechado com elásticos de borracha modelo 18 - Mercur ${ }^{\circledR}$. Utilizaram-se dois sacos (repetições) para colheita das primeiras 24 horas $(0,3,6,12,18$ e 24 horas $)$ e três para as últimas colheitas (48, 72, 96 e 120 horas).

Tabela 1- Composição dos suplementos proteicos

\begin{tabular}{lccc}
\hline & Nível de proteína no & suplemento \\
\cline { 2 - 4 } Ingrediente (\%) & $30 \%$ & $40 \%$ & $50 \%$ \\
\hline Milho & 28,00 & 17,00 & 5,00 \\
Farelo de soja & 15,00 & 15,00 & 15,00 \\
Ureia extrusada & 21 & 32 & 44 \\
Fosfato bicálcico & 10,00 & 10,00 & 10,00 \\
Carbonato de cálcio & 2,00 & 1,75 & 1,50 \\
Enxofre ventilado & 0,00 & 0,25 & 0,50 \\
Núcleo premix ${ }^{2}$ & 4,00 & 4,00 & 4,00 \\
Sal branco & 20,00 & 20,00 & 20,00 \\
Nutricional (\% na base MS) & Suplemento proteico \\
Proteína bruta & 29,21 & 39,49 & 50,38 \\
Matéria seca & 92,37 & 93,44 & 94,86 \\
Proteína degradável no rúmen ${ }^{3}$ & 23,45 & 33,64 & 44,72 \\
Extrato etéreo & 1,69 & 1,56 & 1,41 \\
Carboidratos não-fibrosos $(\mathrm{CNF})^{3}$ & 29,63 & 27,26 & 24,84 \\
Relações entre proteína & & & \\
degradável no rúmen e & 0,79 & 1,45 & 1,80 \\
carboidratos não-fibrosos & 6,23 & 5,84 & 5,43 \\
Fibra em detergente neutro & 45,46 & 50,23 & 55,32 \\
Nutrientes digestíveis totais ${ }^{4}$ & 1,66 & 1,83 & 2,01 \\
Energia metabolizável (Mcal/kg) & 5 & & \\
\hline
\end{tabular}

${ }_{1}^{1}$ Ureia extrusada: níveis de garantia (100\% equivalente proteico e $50 \%$ NDT).

${ }^{2}$ Núcleo Premix: níveis de garantia por kg do produto (S -165 g; Mg - 120 g; Zn $28.000 \mathrm{mg} ; \mathrm{Mn}-9.600 \mathrm{mg} ; \mathrm{Fe}-11.000 \mathrm{mg}$; Co - $1.000 \mathrm{mg}$; I $-800 \mathrm{mg} ; \mathrm{Cu}-$ $12.500 \mathrm{mg} ; \mathrm{Se}-125 \mathrm{mg}$ ).

${ }^{3}$ Calculada conforme descrito por Valadares Filho (2000).

${ }^{4}$ Calculado segundo Weiss (1994).

${ }^{5}$ Segundo NRC (1996). 
Os sacos foram amarrados em grupos de 2 ou 3 em uma corda de náilon com cinco âncoras de ferro ( $100 \mathrm{~g}$ de peso cada) e,antes de serem inseridos no rúmen, os saquinhos foram mergulhados por 10 minutos em balde com água, retirando dois sacos após esse período referentes ao tempo de 0 hora (fração solúvel). Posteriormente, foram colocados no rúmen ao mesmo tempo e retirados conforme seus horários de colheitas. Após a retirada, foram imersos novamente em balde com água antes de serem congelados em freezer $\mathrm{a}-10^{\circ} \mathrm{C}$. Após o descongelamento, procedeu-se à lavagem em lavadora da marca Brastemp ${ }^{\circledR}$, antes de serem colocados em estufa ventilada a $55^{\circ} \mathrm{C}$ por 72 horas para secagem. Foram determinadas as composições químicas das amostras originais e dos resíduos nos tempos $0,3,6$, 12, 24, 48, 72, 96 e 120 horas.

Para a taxa de degradação, aplicou-se o modelo nãolinear de Orskov et al. (1980), até 120 horas (Craig et al., 1984) ajustado conforme descrito por Sampaio (1998):

$$
\operatorname{Deg}(\mathrm{t})=\mathrm{A}-\mathrm{B} * \mathrm{e}^{-\mathrm{c} * \mathrm{t}} \text { para } \mathrm{t}>\mathrm{L}
$$

em que: $A=$ fração solúvel potencialmente degradável; $\mathrm{B}=$ fração potencialmente degradável sob a ação dos microrganismos, se não houvesse lag-time ou tempo de colonização; e c = taxa constante de degradação da fração B.

Nos cálculos da degradabilidade efetiva(DE), utilizou-se o modelo proposto por Orskov \& McDonald (1979):

$$
\mathrm{DE}=\mathrm{S}+((\mathrm{B} 1 \times \mathrm{c}) /(\mathrm{c}+\mathrm{kp})
$$

em que: $\mathrm{S}=$ fração solúvel; $\mathrm{B} 1$ = fração potencialmente degradável pela ação dos microrganismos; e kp = taxa de passagem das partículas pelo rúmen.

As taxas de passagem das partículas nos animais de cada grupo (controle $=0,0242$; suplemento com $50 \%$ de PB $=0,0253$; suplemento com $40 \%$ de $\mathrm{PB}=0,0260$; suplemento com $30 \%$ de $\mathrm{PB}=0,0264$ ) foram calculadas previamente e aplicadas na equação.

As taxas de passagem das fases líquida e sólida da digesta foram estimadas pelos indicadores Co-EDTA $(14,83 \%$ de Co) e fibra mordentada com cromo, respectivamente. Os animais foram mantidos nos piquetes durante todo o período de colheitas e recolhidos ao curral apenas nos horários estabelecidos para as colheitas.

As amostras compostas de forragem foram mordentadas com cromo à base de $12 \%$ da matéria seca da fibra em detergente neutro, utilizando-se dicromato de sódio $\left(\mathrm{Na}_{2} \mathrm{Cr}_{2} \mathrm{O}_{7} \cdot 2 \mathrm{H}_{2} \mathrm{O}\right)$, conforme técnica descrita por Burns et al. (1994). Administrou-se fibra mordente (60 g/animal/ período), às $6 \mathrm{~h}$, diretamente no rúmen, via cânula ruminal.

Fezes foram colhidas diretamente no reto com auxílio de sacos de plástico, que foram posteriormente identificados com etiquetas e submetidos ao congelamento a temperatura de $-17^{\circ} \mathrm{C}$. Os tempos de colheitas foram $0,3,6,9,12,18,24$, $48,72,96,120$ horas.

Foram infundidos diretamente no rúmen $200 \mathrm{~mL}$ de uma solução aquecida a $37^{\circ} \mathrm{C}$ de Co-EDTA ( $20 \mathrm{~g}$ de Co-EDTA + água destilada em quantidade suficiente para $200 \mathrm{~mL}$ ), conforme recomendações de Uden et al. (1980), no mesmo horário da administração da fibra mordente.

As amostras de fezes foram descongeladas, secas em estufa ventilada a $55^{\circ} \mathrm{C}$ por 72 horas e processadas em moinho do tipo Willey em peneira de $2 \mathrm{~mm}$. Dosou-se o teor de cromo em espectrômetro de absorção atômica com chama da marca Perkin Elmer, modelo 5000 com controlador de gases no laboratório da Fundação Centro Tecnológico de Minas Gerais (CETEC).

Amostras de líquido ruminal foram colhidas imediatamente antes ( 0 hora) e após a infusão da solução de cobalto nos seguintes tempos: 3, 6, 9, 12, 18 e 24 horas. $\mathrm{O}$ líquido ruminal foi filtrado em camadas duplas de gaze, retirando-se de cada horário e tratamento uma amostra de $100 \mathrm{~mL}$ colocadas em potes de polietileno com tampas e identificados com etiquetas antes de seu armazenamento em câmara fria $\mathrm{a}-17^{\circ} \mathrm{C}$.

As amostras de líquido ruminal foram mais tarde descongeladas e centrifugadas a $10.000 \mathrm{~g}$ por 15 minutos (Sorvall RC-5B / Refrigerated Superspeed Centrifugue / Du Pont Instruments ${ }^{\circledR}$ ) a temperatura de $4{ }^{\circ} \mathrm{C}$. Procedeu-se à leitura de Co no sobrenadante em espectrofotômetro de absorção atômica no aparelho VARIAN ${ }^{\circledR}$ Spectr AA 220FS /Fast Sequential, conforme Cunnif(1995).

As amostras originais da forragem e dos resíduos da digestibilidade foram secas em estufa ventilada a $55^{\circ} \mathrm{C}$ por 48 horas e processadas em moinho do tipo Willey com peneira de $2 \mathrm{~mm}$. Posteriormente procederam-se às determinações dos teores de matéria seca (MS), proteína bruta (PB) e matéria mineral (MM), segundo AOAC International (Cuniff, 1995), alem da fibra em detergente neutro (FDN) e fibra detergente ácido (FDA) conforme metodologia proposta por Robertson \& Van Soest (1981).

Nas amostras originais da forragem e dos suplementos, determinaram-se também os teores de extrato etéreo (EE), cálcio e fósforo, segundo AOAC International (Cuniff, 1995), assim como os níveis de nitrogênio insolúvel em detergente neutro (NIDN) e nitrogênio insolúvel em detergente ácido (NIDA), conforme recomendação de Valadares Filho (2000).

Nos cálculos das taxas de passagem da fase líquida, os dados das concentrações de Co foram ajustados pelo modelo unicompartimental proposto por Colucci et al. (1990).

O modelo bicompartimental de Grovum \& Williams (1973), descrito abaixo, foi aplicado nos ajustes das 
concentrações de cromo nas estimativas das taxas de passagem da fase sólida.

$\mathrm{O}$ volume de fluido ruminal foi estimado pela relação entre a dose administrada de cobalto e a concentração de equilíbrio (no tempo zero do modelo), e o fluxo ruminal pela multiplicação do valor da taxa de passagem e do volume (Vásquez, 2002).

As estimativas dos tempos de retenção da fase sólida no rúmen e no pós-rúmen foram obtidas pelas recíprocas das respectivas taxas de passagem. O tempo de trânsito corresponde ao tempo percorrido até o aparecimento do indicador $(\mathrm{Cr})$ nas fezes e o tempo de retenção médio, a somatória dos tempos de retenção da fase sólida no rúmen e no pós-rúmen e do tempo de trânsito (Vásquez, 2002).

Estimaram-se o volume do fluido ruminal, pela relação entre a concentração de equilíbrio e a dose administrada de Co; e o tempo de retenção pela recíproca da taxa de passagem da fase líquida. O fluxo de líquidos foi calculado pela multiplicação entre VFR e kp; e a taxa de reciclagem diária, pela divisão das 24 horas do dia pelo TRL (Colucci et al., 1990).

Os resultados obtidos foram submetidos a análises de variância em delineamento quadrado latino com parcelas subdivididas, considerando nas parcelas os quatro tratamentos e nas subparcelas os horários (11 para taxa de passagem das partículas; 7 para taxa de passagem de líquidos; 9 para taxa de degradação) de observaçãode cada $\operatorname{animal}(4)$.

O modelo matemático utilizado para análise de variância foi:

$$
Y_{i j}=\mu+A i+D_{j}+P_{k}+H_{1}+L k j+E_{i j k l},
$$

em que $\mathrm{Y}_{\mathrm{ij}}=$ variável observada no animal $\mathrm{i}$ e na dieta $\mathrm{j}$; $\mu=$ média geral; $\mathrm{A} i=$ efeito animal $i ; \mathrm{D}_{\mathrm{j}}=$ efeito da dieta $\mathrm{j}$;
$\mathrm{P}_{\mathrm{k}}=$ efeito do período $\mathrm{k} ; \mathrm{H}_{1}=$ efeito do horário $1 ; \mathrm{Ljk}=$ ação do período $\mathrm{k}$ sobre a dieta $\mathrm{j} ; \mathrm{E}_{\mathrm{ijkl}}=$ erro aleatório.

Realizou-se estudo sobre os efeitos dos níveis de PB e de EM dos suplementos, assim como de suas interações por intermédio da análise de regressão. Os parâmetros de digestibilidade e da cinética ruminal foram estimados pelo processo iterativo do algoritmo Marquadt, com os procedimentos de modelos não lineares do PROC NLIN do SAS (1985).

\section{Resultados e Discussão}

No decorrer do experimento, foram observados baixos níveis de proteína (PB média de 5,62\%) associados a progressivos aumentos nos teores de fibra e de lignina nas análises da forragem (Tabela 2), semelhantes aos dados registrados em outros trabalhos (Thiago, 1998; Oliveira et al., 2004b), no período de seca.

Não houve diferenças na degradabilidade potencial e efetiva da MS e da PB (Tabela 3), assim como da FDN e FDA (Tabela 4) da forragem, relacionadas à suplementação proteica, visto que a forragem está fortemente associada às características inerentes à planta.

Martim \& Hubberd (1990) avaliaram a suplementação com casca de soja ( 1 a $3 \mathrm{~kg} /$ animal/dia) em novilhosmantidos em pastagens de baixo valor nutricional e observaram aumentos lineares na digestibilidade da matéria orgânica apenas quando substituíram parte da casca por farelo de algodão, comprovando os efeitos da adição proteica à dieta de baixo valor nutricional, o mesmo observado neste estudo.

A suplementação proteica $(30,40$ e $50 \%$ de $\mathrm{PB})$ aumentou a degradabilidade efetiva da $\operatorname{MS}(\mathrm{P}<0,05)$, que

Tabela 2 - Composição química da forragem, com base na matéria seca

\begin{tabular}{|c|c|c|c|c|c|}
\hline \multirow[t]{2}{*}{ Item $(\%)$} & \multicolumn{5}{|c|}{ Mês } \\
\hline & Junho $^{2}$ & Julho & Agosto & Setembro & Outubro \\
\hline Matéria seca & 31,27 & 33,18 & 35,19 & 32,78 & 26,57 \\
\hline Extrato etéreo & 2,58 & 2,14 & 2,09 & 1,89 & 2,26 \\
\hline Cinzas & 6,95 & 4,36 & 4,73 & 5,97 & 5,75 \\
\hline Fibra detergente neutro & 78,30 & 82,31 & 80,13 & 80,75 & 80,11 \\
\hline Fibra detergente ácido & 42,27 & 46,42 & 43,92 & 45,86 & 42,14 \\
\hline Nitrogênio insolúvel em detergente neutro & 0,41 & 0,37 & 0,34 & 0,39 & 0,47 \\
\hline Nitrogênio insolúvel em detergente ácido & 0,37 & 0,28 & 0,21 & 0,24 & 0,31 \\
\hline Fibra detergente neutro com correção de proteína & 75,74 & 80,00 & 78,00 & 78,31 & 77,06 \\
\hline Celulose & 35,44 & 40,13 & 38,37 & 39,32 & 36,65 \\
\hline Hemicelulose & 37,03 & 35,89 & 36,24 & 34,89 & 37,97 \\
\hline Lignina & 5,45 & 5,95 & 5,60 & 6,06 & 4,89 \\
\hline Carboidratos não-fibrosos ${ }^{3}$ & 8,35 & 8,50 & 10,25 & 8,46 & 8,52 \\
\hline Cálcio & 0,39 & 0,37 & 0,40 & 0,39 & 0,36 \\
\hline Nutrientes digestíveis totais 1 & 51,78 & 52,71 & 52,40 & 51,78 & 52,43 \\
\hline
\end{tabular}

${ }_{1}^{1} \mathrm{NDT}=\mathrm{PBD}+\mathrm{CNFD}+\mathrm{FDND}+(\mathrm{EED} \times 2,25)($ Weiss, 1994$)$

${ }^{2}$ Amostra utilizada nos testes de digestibilidade in situ.

${ }^{3} \mathrm{CNF}=100-(\% \mathrm{FDNcp}+\% \mathrm{~PB}+\% \mathrm{EE}+\%$ Cinzas $)($ Weiss, 1994$)$. 
atingiu valores de $48,97 \%$ no casod e dieta com $30 \%$ de $\mathrm{PB}$, a $36,85 \%$, no caso da dieta controle. A degradabilidade efetiva da proteína bruta foi maior $(\mathrm{P}<0,05)$ quando fornecidos suplementos com $30 \%$ e $40 \%$ em comparação ao sal mineral, no entanto houve diferenças entre o suplemento com $50 \%$ de PB e o controle.

Os dados de degradabilidade da proteína bruta obtidos com a suplementação proteica mais concentrada diferem dos observados em outros estudos com forragem de baixo valor nutricional (Steen \& Moore, 1989; Petit \& Flipot, 1992). É possível que nas condições deste trabalho, a oferta de PB ao nível de $50 \%$, tenha sido maior que a demanda microbiana, tendo em vista o volume de oferta de outros nutrientes.

A suplementação proteica com blocos contendo ureia, melaço e minerais (Urea Molasses Mineral Block) a bovinos a pasto promoveu aumento na digestibilidade da matéria orgânica e da PB nos trabalhos de Toppo et al. (1997).

No entanto, por sua forte relação com o alimento, os resultados da suplementação proteica sobre a digestibilidade da matéria seca e das frações fibrosas da forragem têm sido controversos.

Petit \& Flipot (1992) compararam os efeitos da adição proteica na forma degradável (ureia) e não-degradável no rúmen (farinha de peixe) e não observaram diferenças na digestibilidade da matéria seca, da fibra em detergente neutro e da fibra em detergente ácido, diferentemente dos resultados encontrados neste estudo para matéria seca e fibra detergente neutro e similar aos resultados da fibra em detergente ácida.

O uso de suplementos múltiplos promove aumento na degradabilidade efetiva, mas não modifica a degradabilidade potencial da MS de diversas forragens incubadas no rúmen

Tabela 3 - Degradabilidade e taxa de degradação da matéria seca e da proteína bruta do capim-marandu

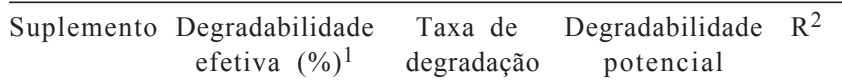

$(/ \mathrm{h}) \quad(\%)$

\begin{tabular}{lcccc}
\hline & \multicolumn{5}{c}{ Matéria seca } \\
$30 \%$ de PB & $48,97 \mathrm{a}$ & $0,034 \mathrm{a}$ & $87,13 \mathrm{a}$ & 93,55 \\
$40 \%$ de PB & $45,97 \mathrm{a}$ & $0,033 \mathrm{a}$ & $83,74 \mathrm{a}$ & 92,47 \\
$50 \%$ de PB & $42,19 \mathrm{a}$ & $0,036 \mathrm{a}$ & $76,85 \mathrm{a}$ & 94,54 \\
Controle & $36,85 \mathrm{~b}$ & $0,029 \mathrm{a}$ & $67,74 \mathrm{a}$ & 93,96 \\
& \multicolumn{5}{c}{ Proteína bruta } \\
& & & \\
$30 \%$ de PB & $43,72 \mathrm{a}$ & $0,041 \mathrm{a}$ & $79,72 \mathrm{a}$ & 78,87 \\
$40 \%$ de PB & $41,44 \mathrm{a}$ & $0,040 \mathrm{a}$ & $77,86 \mathrm{a}$ & 71,74 \\
$50 \%$ de PB & $36,35 \mathrm{ab}$ & $0,039 \mathrm{a}$ & $72,43 \mathrm{a}$ & 82,89 \\
Controle & $33,23 \mathrm{~b}$ & $0,035 \mathrm{a}$ & $64,20 \mathrm{a}$ & 81,42 \\
\hline
\end{tabular}

Médias com letras diferentes na mesma coluna diferem $(\mathrm{P}<0,05)$ pelo teste SNK.

${ }^{1}$ Valores calculados aplicando-se as taxas de passagens de partículas obtidas pelo modelo de Grovum e Williams (1973). de novilhos de corte (Oliveira et al., 2004a). Neste trabalho, a degradabilidade efetiva da matéria seca no grupo controle $(36,85 \%)$ foi inferior a observada com a suplementação proteica $(48,97,45,97$ e $42,19 \%)$.

A degradabilidade potencial da fibra detergente neutro foi semelhante entre os grupos, oscilando de 54,87 (controle) a 64,90 (30\% de PB), enquanto a degradabilidade efetiva aumentou com a suplementação proteica $(\mathrm{P}<0,05)$, passando de 22,06 (controle) para 30,05\% (30\% de PB) (Tabela 4).

Não foram observadas diferenças nas digestibilidades de fibra em detergente neutro entre os animais que receberam suplementação proteica, apesar dos níveis de milho nos suplementos ( 28,17 e $5 \%$ respectivamente), o que pode ter sido causado pelos baixos níveis de suplementação ou pela possível associação favorável entre as fontes de nitrogênio e carboidratos nesta situação.

As taxas de passagem no rúmen variaram de $0,0243 /$ hora em (controle) a 0,0264/hora em ( $30 \%$ de PB) (Tabela 5). Não foram observadas diferenças nas taxas de passagem entre os grupos que receberam proteína, porém os animais que receberam suplementos proteicos com maiores níveis de carboidratos solúveis (30\% e 40\%) apresentaram taxa de passagem superior $(\mathrm{P}<0,05)$ à observada no grupo controle.

Oliveira et al. (2004a) encontraram valores de 0,0234 a $0,0300 \%$ hora para a matéria seca e de 0,0113 a 0,0313 para a proteína bruta. Freeman et al. (1992) relataram valores de 0,026 a $0,032 \%$ hora para taxa de degradação da fibra em detergente neutro, semelhantes aos relatados por Hess et al. (1994), de 0,024 a $0,032 \%$ hora e aos obtidos neste trabalho $(0,027$ a $0,0335 \%$ hora $)$.

Segundo Mertens (1994), em dietas de baixo valor nutricional, prevalece o modelo físico como mecanismo de

Tabela 4 - Degradabilidade e taxa de degradação das frações fibrosas do capim-marandu

\begin{tabular}{lcccc}
\hline $\begin{array}{l}\text { Suplemento } \\
\text { proteico }\end{array}$ & $\begin{array}{c}\text { Degradabilidade } \\
\text { efetiva }(\%)^{1}\end{array}$ & $\begin{array}{c}\text { Taxa de } \\
\text { degradação } \\
(\% \mathrm{~h})\end{array}$ & $\begin{array}{c}\text { Degradabilidade } \\
\text { potencial } \\
(\%)\end{array}$ & $\mathrm{R}^{2}$ \\
\hline \multicolumn{5}{c}{ Fibra em detergente neutro } \\
$30 \%$ de PB & $30,05 \mathrm{a}$ & $0,033 \mathrm{a}$ & $64,90 \mathrm{a}$ & 92,60 \\
$40 \%$ de PB & $29,37 \mathrm{a}$ & $0,032 \mathrm{a}$ & $64,69 \mathrm{a}$ & 90,90 \\
$50 \%$ de PB & $27,00 \mathrm{a}$ & $0,029 \mathrm{a}$ & $61,50 \mathrm{a}$ & 94,70 \\
Sal mineral & $22,06 \mathrm{~b}$ & $0,027 \mathrm{a}$ & $54,87 \mathrm{a}$ & 95,30 \\
\multicolumn{5}{c}{ Fibra em detergente ácido } \\
$30 \%$ de PB & $16,75 \mathrm{a}$ & $0,028 \mathrm{a}$ & $38,69 \mathrm{a}$ & 94,60 \\
$40 \%$ de PB & $14,82 \mathrm{a}$ & $0,026 \mathrm{a}$ & $36,50 \mathrm{a}$ & 92,80 \\
$50 \%$ de PB & $13,95 \mathrm{a}$ & $0,025 \mathrm{a}$ & $34,20 \mathrm{a}$ & 89,50 \\
Sal mineral & $12,19 \mathrm{a}$ & $0,025 \mathrm{a}$ & $30,70 \mathrm{a}$ & 93,60 \\
\hline
\end{tabular}

Médias com letras diferentes na mesma coluna diferem $(\mathrm{P}<0,05)$ pelo teste SNK. ${ }^{1}$ Valores calculados aplicando-se as taxas de passagens de partículas obtidas pelo modelo de Grovum \& Williams (1973). 
Tabela 5 - Cinética das partículas pelo trato gastrointestinal de bovinos Nelore em pastagem de capim-marandu rebecendo suplementos $\operatorname{proteicos}^{1}$

\begin{tabular}{|c|c|c|c|c|}
\hline \multirow[t]{2}{*}{ Item } & \multicolumn{4}{|c|}{ Suplemento proteico } \\
\hline & Controle & $30 \% \mathrm{~PB}$ & $40 \%$ PB & $50 \% \mathrm{~PB}$ \\
\hline Taxa de passagem no rúmen (/hora) & $0,0243 b$ & $0,0264 \mathrm{a}$ & $0,0260 \mathrm{a}$ & $0,0254 \mathrm{ab}$ \\
\hline Tempo de trânsito (hora) & $12 \mathrm{~h} 26^{\prime} \mathrm{a}$ & $11 \mathrm{~h} 57$ 'a & $10 \mathrm{~h} 25$ 'a & $11 \mathrm{~h} 32^{\prime} \mathrm{a}$ \\
\hline Tempo de retenção no rúmen (hora) & $41 \mathrm{~h} 9$ 'a & $37 \mathrm{~h} 53^{\prime} \mathrm{b}$ & $38 \mathrm{~h} 28^{\prime} \mathrm{ab}$ & 39 h22'a \\
\hline Tempo de retenção pós ruminal (hora) & $27 \mathrm{~h} 10^{\prime} \mathrm{ab}$ & $25 \mathrm{~h} 50^{\prime} \mathrm{b}$ & $25 \mathrm{~h} 26^{\prime} \mathrm{b}$ & 29 h20'a \\
\hline Tempo médio de retenção (hora) & $80 \mathrm{~h} 45^{\prime} \mathrm{a}$ & $75 \mathrm{~h} 40^{\prime} \mathrm{b}$ & $74 \mathrm{~h} 19^{\prime} \mathrm{b}$ & $80 \mathrm{~h} 14^{\prime} \mathrm{a}$ \\
\hline $\mathrm{R}^{2}$ & 82,67 & 83,99 & 78,95 & 84,74 \\
\hline
\end{tabular}

Médias com letras diferentes na mesma linha diferem $(\mathrm{P}>0,05)$ pelo teste SNK.

${ }^{1}$ Valores calculados pelo modelo de Grovum \& Williams (1973).

controle do consumo, desta forma, maiores taxas de passagem pelo rúmen são consequência direta da melhor oferta de nutrientes via suplementação proteica. Krysl et al. (1989) relataram taxas de passagem de partículas de 0,031/h a 0,034/h, enquanto Freeman et al. (1992) relataram valores de $0,022 / \mathrm{h}$ a $0,025 / \mathrm{h}$ para animais em pastagem sem e com suplementação proteica, respectivamente.

O tempo médio de retenção foi maior nos animais sob suplementação com $50 \%$ de PB e naqueles do grupo controle $(\mathrm{P}<0,05)$ em relação aos que receberam suplementos com 30 ou $40 \%$ de proteína. Os valores obtidos neste trabalho assemelham-se aos relatados por Freeman et al. (1992), de 69,0 horas (com suplementação) a 78,9 horas (sem suplementação), porém são superiores aos encontrados por Krysl et al. (1989), média de 52h42'.

Considerando apenas a fração fibrosa da forragem, a porção mais lignificada e menos digestível das fibras tende a apresentar altas taxas de passagem superiores e sair mais rapidamente do rúmen que as frações mais digestíveis (Tamminga et al., 1989). Avaliações precisas das frações fibrosas da forragem e suas associações com as taxas de passagem, degradabilidade e consumo são determinantes em estudos sobre o estabelecimento das condições mais ajustadas da suplementação proteica.
A taxa de passagem obtida quando fornecido o suplemento com $30 \%$ de $\mathrm{PB}(\mathrm{kp}=0,099)$ foi $12,5 \%$ maior $(\mathrm{P}<0,05)$ que a encontrada com a oferta de sal mineral $(\mathrm{kp}=0,088)$ (Tabela 6), e a média de taxa de passagem nos animais sob suplementação (0,095) 11,4\%, foi superior $(\mathrm{P}<0,05)$ à dos animais controle.

Hess et al. (1994) relataram taxa de passagem de 7,7\% para animais sem suplementação com proteína e de 8,3 a $8,6 \%$ nos animais controle, resultados semelhantes aos encontrados por Caton et al. (1988) e Freeman et al. (1992) e diferentes dos obtidos por Krysl et al. (1989) em estudos sobre suplementação proteica.

As taxas de passagem de líquidos, de forma harmoniosa com a fisiologia ruminal, podem melhorar o aporte de nutrientes que chegam ao intestino, principalmente de proteína microbiana, aumentando o desempenho produtivo de animais a pasto.

Os resultados de taxa de passagem obtidos neste trabalho parecem ter sido influenciados pelo aumento do consumo, corroborando a afirmativa de Adams \& Kartchner (1984). As partículas que deixam o rúmen pelo orifício retículo-omasal encontram-se em suspensão (Poppi et al., 1980), ajudando a esclarecer as respostas semelhantes obtidas para as fases líquidas e sólidas neste trabalho.

Tabela 6 - Cinética da fase líquida da digesta pelo trato gastro intestinal de bovinos Nelore em pastagem de capim-marandu ${ }^{1}$

\begin{tabular}{|c|c|c|c|c|}
\hline \multirow[t]{2}{*}{ Item } & \multicolumn{4}{|c|}{ Suplemento proteico } \\
\hline & Sal mineral & $30 \% \mathrm{~PB}$ & $40 \% \mathrm{~PB}$ & $50 \% \mathrm{~PB}$ \\
\hline Volume (L) & $54,790 \mathrm{a}$ & $54,678 \mathrm{a}$ & $54,986 a$ & $55,043 a$ \\
\hline Tempo de retenção no rúmen (hora) & $11 \mathrm{~h} 46^{\prime} \mathrm{a}$ & $10 \mathrm{~h} 6$ 'b & $10 \mathrm{~h} 52^{\prime} \mathrm{ab}$ & $10 \mathrm{~h} 45^{\prime} \mathrm{ab}$ \\
\hline Fluxo de líquidos (L/hora) & $4 \mathrm{~h} 40$ 'b & $5 \mathrm{~h} 25^{\prime} \mathrm{a}$ & $5 \mathrm{~h}, 3$ 'ab & $5 \mathrm{~h} 7$ 'a \\
\hline Taxa de reciclagem diária (ciclos/dia) & 2,040 & 2,376 & 2,208 & 2,232 \\
\hline
\end{tabular}

Médias com letras diferentes na mesma linha diferem $(\mathrm{P}>0,05)$ pelo teste $\mathrm{SNK}$.

${ }^{1}$ Valores calculados pelo modelo de Colucci et al. (1990). 


\section{Conclusões}

O uso de suplementos proteicos contendo 30 e $40 \%$ de proteína bruta e fornecidos no nível de $0,1 \%$ do peso vivo para bovinos consumindo forragem de baixo valor nutricional melhora os processos de digestão, por aumentar a degradabilidade efetiva da matéria seca, da proteína bruta e da fibra detergente neutro e por acelerar a taxa de passagem, reduzindo o tempo médio de retenção no rúmen.

\section{Referências}

AADAMS, D.C.; KARTCHNER, R.J. Effect of level of forage intake on rumen ammonia, $\mathrm{pH}$, liquid volume and liquid dilution rate in beef cattle. Journal of Animal Science, v.58, p.708-716, 1984.

ARELOVICH, H.M.; OWENS, F.N.; HORN, G.W. et al. Effects of supplemental zinc and manganese on ruminal fermentation, forage intake, and digestion by cattle fed prairie hay and urea. Journal of Animal Science, v.78, p.2972-2979, 2000.

BURNS, J.C.; POND, K.R.; FISHER, D.S. Measurements of forage intake. In: FAHEY JR., G.C.(Ed.) Forage quality, evaluation and utilization. Ohio: American Society of Agronomy, 1994. p.494-532.

CASS, J.L.; RICHARDSON, C.R.; SMITH K.J. Evaluation of slow ammonia release from urea/calcium compounds. Journal of Animal Science, v.72, p.234, 1994 (supp. 1).

CATON, J.S.; FREEMAN, A.S.; GALYEAN, M.L. Influence of protein supplementation on forage intake, in situ forage disappearance, ruminal fermentation and digesta passage rates in steers grazing dormant blue grama rangeland. Journal of Animal Science, v.66, p.2262-2271, 1988.

COLUCCI, P.E.; MACLEOD, G.K.; GROVUM, W.L. et al. Digesta kinetics in sheep and cattle fed diets with different forage to concentrate ratios at high and low intakes. Journal of Dairy Science, v.73, p.2143-2156, 1990.

COOK, C.W.; THORNE, J.L.; BLAKE, J.T. et al. Use of am esophageal fistula cannula forage for collecting forage samples by grazing sheep. Journal of Animal Science, v.17, n.1, p.189-193, 1958

CRAIG, W.M.; HONG, B.J.; BRODERICK, G.A. et al. In vitro inoculum enriched with particle associated microorganism for determining rates of fiber digestion and protein degradation. Journal of Dairy Science, v.46, n.5, p.2176-2182, 1984.

CUNNIFF, P. Official methods of analysis of AOAC International. 16.ed. Arlington: AOAC International, 1995. v.1.

ELLIS, W.C.; MATIS, J.H.; HILL, T.M. et al. Methodology for estimating digestion and passage kinetics of forage. In: FAHEY JR., G.C., MOSER, L.E., MERTENS, D.R., et al. (Eds.) National Conference on Forage Quality, Evaluation, and Utilization. Madison: Soil Science Society of America. 1994. p.682-756.

EUCLIDES, V.P.B.; MACEDO, M.C.M.; OLIVEIRA, M.P. Avaliação de diferentes métodos de amostragem (para se estimar o valor nutritivo da forragem) sob pastejo. Revista Brasileira de Zootecnia, v.21, n.4, p.691-702, 1992.

FREEMAN, A.S.; GALYEAN, M.L.; CATON, J.S. Effects of supplemental protein percentage and feeding level on intake, ruminal fermentation, and digesta passage in beef steers fed prairie hay. Journal of Animal Science, v.70, p.1562-1572, 1992.

GOROSITO, A.R.; RUSSELL, J.B.; VAN SOEST, P.J. Effect of carbon-4 and carbon-5 volatile fatty acids on digestion of plant cell wall in vitro. Journal of Dairy Science, v.68, n.4, p.840-847, 1985 .
GROVUM, W.L.; WILLIAMS, V.J. Rate of passage of digest in sheep. 4. Passage of marker through the alimentary tract and the biological relevance of rate-constants derived from the chances in concentration of marker in faeces. British Journal of Nutrition, v.30, p.313-329, 1973.

HENNESSY, D.W.; WILLIAMSON, P.J. Feed intake and liveweight of cattle on subtropical native pasture hays. II. The effect of urea and maize flour, or protected-casein. Australian Journal of Agricultural Research, v.41, p.1179-1185, 1990.

HENNESSY, D.W.; KOHUN, P.J.; WILLIAMSON, P.J. et al. The effect of nitrogen and protein supplementation on feed intake, growth and digestive function of steers with different Bos indicus, Bos taurus genotypes when fed a low quality grass hay. Australian Journal of Agricultural Research, v.46, p.1121-1136, 1995.

HESS, B.W.; PARK, K.K.; KRYSL, L.J. et al. Supplemental protein for beef cattle grazing dormant intermediate wheat grass pasture: Effects on nutrient quality, forage intake, digesta kinetics, grazing behavior, ruminal fermentation, and digestion. Journal of Animal Science, v.72, p.2113-2123, 1994.

KANG-MEZNARICH, J.H.; BRODERICK, G.A. Effects of incremental urea supplementation on ruminal ammonia concentration and bacterial protein formation. Journal of Animal Science, v. 51, p.422-431, 1980

KRYSL, L.J.; BRANINE, M.E.; CHEEMA, A.U. et al. Influence of soybean meal and sorghum grain supplementation on intake, digesta kinetics, ruminal fermentation, site and extent of digestion and microbial protein synthesis in beef steers grazing blue grama rangeland. Journal of Animal Science, v.67, p.3040-3051, 1989.

MARTIM, S.K.; HIBBERT, C.A. Intake and digestibility of lowquality native grass hay by beef cows supplemented with graded levels of soybean hulls. Journal of Animal Science, v.68, p.4329-4325, 1990.

MEHREZ, AZ.; ORSKOV, E.R.; McDONALD, I. Rates of rumen fermentation in relation to ammonia concentration. British Journal Nutrition, v.38, p.437-448, 1966.

MERTENS, D.R. Regulation of forage intake. In: FAHEY JR., G.C. (Ed.) Forage quality, evaluation and utilization. Ohio: American Society of Agronomy, 1994. p.450-493.

NATIONAL RESEARCH COUNCIL - NRC. Nutrient requirements of beef cattle. 7.ed. Washington, D.C.: National Academic Press, 1996. 244p.

OLDHAM, J.D. Protein-energy interrelationships in dairy cows. Journal of Dairy Science, v.67, p.1090-1114, 1984.

OLIVEIRA, E.R.; PAIVA, P.C.A.; BABILONIA, J.L. et al. Degradabilidade in situ da matéria seca, proteína bruta e fibra em detergente neutro, de diferentes gramíneas, em novilhos suplementados com misturas múltiplas. Ciência e Agrotecnologia, v.28, p.425-430, 2004

OLIVEIRA, L.O.F.; SALIBA, E.O.S.; RODRIGUEZ, N.M. et al. Consumo e digestibilidade de novilhos Nelore sob pastagem suplementados com misturas múltiplas. Arquivo Brasileiro de Medicina Veterinária e Zootecnia, v.56, n.1, p.61-68, 2004.

ORSKOV, E.R.; DeB HOVEEL, F.D.; MOULD, F. Uso de la técnica de la bolsa de naylon para la evaluación de los alimentos. Producción Animal Tropical, v.5, p.213-233, 1980.

ORSKOV, E.R.; McDONALD, I. The estimation of protein degradability in the rumen from incubation measurements weighted according to rate of passage. Journal of Agricultural Science, v.92, p.499-503, 1979.

PETIT, H.V.; FLIPOT, P.M. Feed utilization of beef steers fed grass as hay or silage with or without nitrogen supplementation. Journal of Animal Science, v.70, p.876-883, 1992.

POPPI, D.P.; HORTON, B.W.; MINSON, D.J. et al. The validity of the critical size theory particles leaving the rumen. Journal of Agricultural Science, v.94, p.275-286, 1980.

ROBERTSON, J.B.; VAN SOEST, P.J. The detergent system of analysis and its application to human foods. In: JAMES, W.P.T.; 
THEANDER, O. (Eds). The analysis of dietary fiber in food. New York: Marcel Dekker, 1981. p.123-158.

RUSSELL, J.B.; O'CONNOR, J.D.; FOX D.G. et al. A net carbohydrate and protein system for evaluating cattle diets: I. Ruminal fermentation. Journal of Animal Science, v.70, n.11, p.3551-3561, 1992.

SAMPAIO, I.B.M. Estatística aplicada à experimentação animal. Belo Horizonte: Fundação de Ensino e Pesquisa em Medicina Veterinária e Zootecnia, 1998. 221p.

SATTER, L.D.; SLYTER, L.L. Effect of ammonia concentration on rumen microbial protein production in vitro. British Journal of Nutrition, v.32, p.199-208, 1974.

SONG, M.K.; KENNELY, J.J. Ruminal fermentation pattern, bacterial population and ruminal degradation of feed ingredients as influenced by ruminal ammonia concentration. Journal of Animal Science, v.68, p.1110-1120, 1990.

STATISTICAL ANALYSIS SYSTEM - SAS. SAS ${ }^{\circledR}$ user guide: statistics. 5.ed. Cary: SAS Institute, 1985. 956p.

STEEN, R.W.J.; MOORE, C.A. A comparison of silage-based and dried forage-based diets, and the effect of protein supplementation of a silage-based diet for finishing beef cattle. Animal Production, v.49, p.233-240, 1989.

TAMMINGA, S.; ROBINSON, P.H.; VOGT, M. et al. Rumen ingest a kinetics of cell wall components in dairy cows. Animal Feed Science Technology, v.1, p.49-57, 1989.
THIAGO, L.R.L.S. Suplementação de bovinos em pastejo. In: Curso sobre suplementação mineral em bovinos. Campo Grande: EMBRAPA-CNPGC, 1998. p.50-69.

TOPPO, S.; VERMA, A.K.; DASS, R.S. et al. Nutrient utilization and rumen fermentation pattern in crossbred cattle fed different planes of nutrition supplemented with urea molasses mineral block. Animal Feed Science Technology, v.64, p.101-112, 1997.

UDEN, P.; COLLUCCI, P.E.; VAN SOEST, P.J. Investigation on chromium, cerium and cobalt as markers in ingest. Rate passage studies. Journal Science Food and Agriculture, v.31, p.625-632, 1980.

VALADARES FILHO, S.C. Nutrição e avaliação de alimentos e tabelas de composição de alimentos para bovinos. In: REUNIÃO ANUAL DA SOCIEDADE BRASILEIRA DE ZOOTECNIA, 37., 2000, Viçosa, MG. Anais... Viçosa, MG: Sociedade Brasileira de Zootecnia, 2000. p.267-337.

VAN SOEST, P.J. Nutritional ecology of the ruminant. 2.ed. Ithaca: Cornell University, 1994. 476p.

VÁSQUEZ, E.F.A. Suplementação com carboidratos não estruturais para novilhas mestiças Holandês-Zebu em pastagem de Panicum maximum cv. Mombaça. 2002. 113f. Tese (Doutorado em Ciência Animal) - Escola de Veterinária, Belo Horizonte.

WEISS, W.P. Estimation of digestibility of forages by laboratory methods. In: FAHEY JR, G.C. (Eds.) Forage quality, evaluation and utilization. Ohio: American Society of Agronomy, 1994. p.644-681. 